\title{
Life-Saving Therapy versus Symptom Relief: Anti-Platelet Agents and Opioids in Coronary Intervention
}

\author{
Daniel Duerschmied ${ }^{1}$ Christoph Bode ${ }^{1}$ \\ ${ }^{1}$ Department of Cardiology and Angiology I, Heart Center, \\ Faculty of Medicine, University of Freiburg, Freiburg, Germany \\ Thromb Haemost 2018;118:1350-1351.
}

In this issue of Thrombosis and Haemostasis, Ibrahim et al from Johns Hopkins University School of Medicine, Baltimore, Maryland, United States, add important findings to the increasing body of evidence suggesting that opioid therapy reduces anti-platelet efficacy. ${ }^{1}$ Several studies have previously revealed that morphine delays gastrointestinal absorption of orally administered anti-platelet agents. Together, these data challenge widely used clinical practice.

Current guidelines recommend that titrating intravenous opioids to relieve pain should be considered in patients with ST-elevation myocardial infarction (STEMI) (class IIa, level C recommendation). ${ }^{2}$ However, weighing in the available evidence, the guidelines also caution that the use of morphine diminishes the effects of all oral $\mathrm{P}_{2} \mathrm{Y}_{12}$ inhibitors approved for the treatment of acute coronary syndrome, such as clopidogrel, ticagrelor, and prasugrel. ${ }^{3-7}$ This caveat leaves several questions unanswered: First, how relevant is this drug interaction in an era with decreasing pre-hospital pre-loading with an oral $\mathrm{P}_{2} \mathrm{Y}_{12}$ inhibitor? Second, is it really a class effect of all opioids or rather a morphine-specific problem? Third, which alternative treatment could offer symptom relief without interfering with anti-platelet therapy?

First, guidelines recommend prasugrel or ticagrelor loading before (or at latest at the time of) percutaneous coronary intervention (PCI) in STEMI. ${ }^{2}$ However, today, loading with prasugrel is deferred until the coronary anatomy is known in most patients with myocardial infarction (according to the Triton-TIMI-38 design), because the comparison of prasugrel at the time of percutaneous coronary intervention (PCI) or as pretreatment at the time of diagnosis in patients with non-ST elevation myocardial infarction (ACCOAST) trial suggested that pre-loading with prasugrel increased bleeding complications. ${ }^{8}$ Unfortunately, this conclusion did not take into account that ACCOAST examined patients with non-STEMI (NSTEMI) only and extrapolation to patients with STEMI is problematic. In

received

June 28, 2018

accepted

June 28, 2018

\begin{abstract}
Address for correspondence Christoph Bode, MD, Department of Cardiology and Angiology I, Heart Center, Faculty of Medicine, University of Freiburg, Freiburg, Germany

(e-mail: christoph.bode@universitaets-herzzentrum.de).
\end{abstract}

STEMI patients, the Administration of Ticagrelor in the Cath Lab or in the Ambulance for New ST Elevation Myocardial Infarction to Open the Coronary Artery (ATLANTIC) trial found beneficial effects of pre-loading with ticagrelor with lower rates of stent thrombosis, resulting in the strong recommendation for initiating $\mathrm{P}_{2} \mathrm{Y}_{12}$ inhibition before or during PCI for STEMI (class I, level A). ${ }^{9}$ An ATLANTIC sub-group analysis showed that morphine delayed the onset of ticagrelor action in STEMI, which was confirmed independently recently. ${ }^{10}$ In addition, immediate post-PCI loading with prasugrel was also affected by pre-treatment with morphine in patients with STEMI. ${ }^{6}$ In conclusion, both, pre- and post-PCI loading with a $\mathrm{P}^{2} \mathrm{Y}_{12}$ inhibitor are common and both are associated with delayed onset of action under co-treatment with an opioid. Since morphine is also still routinely used in patients with myocardial infarction, these drug interactions are indeed important. Larger trials would be required to assess the influence of opioid-oral P2 $\mathrm{Y}_{12}$ inhibitor interactions on clinical outcomes. According to current knowledge, however, intravenous P2 $_{12}$ inhibition with cangrelor is effective irrespective of opioid use. ${ }^{11}$ Another alternative may be crushed sublingual ticagrelor, ${ }^{12}$ although this needs verification in a trial with opioid co-medication.

The second question was addressed directly by Ibrahim and colleagues, who examined the more and more frequently used fentanyl (the preferred opioid in U.S. catheterization laboratories). They publish here the complete dataset of platelet testing in the Platelet Aggregation with tiCagrelor Inhibition and FentanYl (PACIFY) trial, which was made available earlier this year in a research letter. ${ }^{13}$ Now, the authors report that platelet reactivity was higher in fentanyl-treated patients 2 hours after administration of a regular ticagrelor formulation in patients undergoing elective PCI. This was associated with a slightly higher level of troponin-I ( 7 vs. $12 \mathrm{ng} / \mathrm{L}$ ), but no other clinical findings in this 212-patient cohort. The conclusion (c) 2018 Georg Thieme Verlag KG
Stuttgart · New York
DOI https://doi.org/ 10.1055/s-0038-1667173. ISSN 0340-6245. 
from these results must be that the interaction between opioids and oral $\mathrm{P}_{2} \mathrm{Y}_{12}$ inhibitors has to be considered a class effect at least until proof of the contrary is provided. The pharmacological and pathophysiological context is plausible (impaired gastric motility and drug absorption) and data with morphine and fentanyl are coherent. Although PACIFY was a rather small trial and conducted in a single-centre setting (only 35 patients with fentanyl and 35 patients without fentanyl underwent $\mathrm{PCI}$ ), it is conclusive. A major limitation of the PACIFY trial is the exclusion of patients with NSTEMI or STEMI because opioid use is unnecessary in almost all elective PCIs-a basically painless intervention when arterial access is performed under local anaesthesia.

Considering the interaction between opioids and oral $\mathrm{P}_{2} \mathrm{Y}_{12}$ inhibitors, alternative anti-anginal treatment for patients with NSTEMI or STEMI should be highlighted. ${ }^{2}$ Early intravenous $\beta$-blockers are effective for controlling angina (and prevent ventricular arrhythmias) in normotensive patients with a normal heart rate. Nitrates can be considered in all patients with hypertension or heart failure in the absence hypotension, right ventricular infarction and phosphodiesterase inhibitor consumption in the previous 48 hours. Immediate anti-thrombotic treatment with aspirin and heparin (preventing total vessel occlusion) in combination with anti-anginal management and a benzodiazepine in anxious patients will often suffice for symptom relief, making opioids dispensable.

Taken together, the current and described previous studies should improve the acute management of myocardial infarction. If alternative anti-anginal strategies are consequently applied, opioid treatment may become obsolete in the majority of cases-and is already obsolete in elective PCI. Intravenous $\mathrm{P}_{2} \mathrm{Y}_{12}$ inhibitor administration remains a viable option for patients in severe pain, who still require effective analgesia by opioid titration.

Conflict of Interest

None.

\section{References}

1 Ibrahim K, Shah R, Goli R, et al. Fentanyl delays the platelet inhibition effects of oral ticagrelor: full report of the PACIFY randomized clinical trial. Thromb Haemost 2017;118(08): $1409-1418$
2 Ibanez B, James S, Agewall S, et al; ESC Scientific Document Group. 2017 ESC Guidelines for the management of acute myocardial infarction in patients presenting with ST-segment elevation: the Task Force for the management of acute myocardial infarction in patients presenting with ST-segment elevation of the European Society of Cardiology (ESC). Eur Heart J 2018;39(02):119-177

3 Hobl EL, Stimpfl T, Ebner J, et al. Morphine decreases clopidogrel concentrations and effects: a randomized, double-blind, placebocontrolled trial. J Am Coll Cardiol 2014;63(07):630-635

4 Parodi G, Bellandi B, Xanthopoulou I, et al. Morphine is associated with a delayed activity of oral antiplatelet agents in patients with ST-elevation acute myocardial infarction undergoing primary percutaneous coronary intervention. Circ Cardiovasc Interv 2014;8 (01):e001593

5 Kubica J, Adamski P, Ostrowska M, et al. Morphine delays and attenuates ticagrelor exposure and action in patients with myocardial infarction: the randomized, double-blind, placebo-controlled IMPRESSION trial. Eur Heart J 2016;37(03):245-252

6 Flierl U, Zauner F, Sieweke JT, et al. Efficacy of prasugrel administration immediately after percutaneous coronary intervention in ST-elevation myocardial infarction. Thromb Haemost 2017;117 (01):99-104

7 Farag M, Spinthakis N, Srinivasan M, Sullivan K, Wellsted D, Gorog DA. Morphine analgesia pre-PPCI is associated with prothrombotic state, reduced spontaneous reperfusion and greater infarct size. Thromb Haemost 2018;118(03):601-612

8 Montalescot G, Collet JP, Ecollan P, et al; ACCOAST Investigators. Effect of prasugrel pre-treatment strategy in patients undergoing percutaneous coronary intervention for NSTEMI: the ACCOAST-PCI study. J Am Coll Cardiol 2014;64(24):2563-2571

9 Montalescot G, van 't Hof AW, Lapostolle F, et al; ATLANTIC Investigators. Prehospital ticagrelor in ST-segment elevation myocardial infarction. N Engl J Med 2014;371(11):1016-1027

10 Silvain J, Storey RF, Cayla G, et al. P2Y12 receptor inhibition and effect of morphine in patients undergoing primary PCI for STsegment elevation myocardial infarction. The PRIVATE-ATLANTIC study. Thromb Haemost 2016;116(02):369-378

11 Cohen MV, Downey JM. Combined cardioprotectant and antithrombotic actions of platelet $\mathrm{P} 2 \mathrm{Y} 12$ receptor antagonists in acute coronary syndrome: just what the doctor ordered. J Cardiovasc Pharmacol Ther 2014;19(02):179-190

12 Niezgoda P, Sikora J, Barańska M, et al. Crushed sublingual versus oral ticagrelor administration strategies in patients with unstable angina. A pharmacokinetic/pharmacodynamic study. Thromb Haemost 2017;117(04):718-726

13 McEvoy JW, Ibrahim K, Kickler TS, et al. Effect of intravenous fentanyl on ticagrelor absorption and platelet inhibition among patients undergoing percutaneous coronary intervention: the PACIFY randomized clinical trial (platelet aggregation with ticagrelor inhibition and fentanyl). Circulation 2018;137(03):307-309 